\begin{tabular}{|c|c|c|}
\hline()$_{\text {SiiRT }}^{1}$ & $\begin{array}{c}\text { Türkiye Tarımsal Araştırmalar Dergisi } \\
\text { dergipark.org.tr/tutad }\end{array}$ & $\begin{array}{l}\text { Turk J Agric Res } \\
\text { 2021, 8(1): 116-124 } \\
\text { ○ TÜTAD } \\
\text { ISSN: 2148-2306 }\end{array}$ \\
\hline $\begin{array}{l}\text { UNNIVERSITESI } \\
\text { Bulimin Yyüumda }\end{array}$ & Derleme / Review & $\begin{array}{l}\text { e-ISSN: } 2528-858 \mathrm{X} \\
\text { doi: } 10.19159 / \text { tutad.774385 }\end{array}$ \\
\hline
\end{tabular}

\title{
İnsektisitlerin Böcekler Üzerindeki Subletal Etkileri
}

\author{
Saliha Selma ŞAHIN, Mehmet KEÇECI' \\ Malatya Turgut Özal Üniversitesi, Ziraat Fakültesi, Bitki Koruma Bölümü, Malatya, TÜRKIYE
}

\begin{tabular}{ll}
\hline \multicolumn{1}{c}{ Geliş Tarihi/Received: 27.07 .2020} & Kabul Tarihi/Accepted: 19.01 .2021 \\
\hline ORCID ID (Yazar surasma göre / by author order) & \\
(D)orcid.org/0000-0002-1458-5252 (Dorcid.org/0000-0001-8589-8152 & \\
"Sorumlu Yazar/Corresponding Author: kececitr@yahoo.com &
\end{tabular}

"Sorumlu Yazar/Corresponding Author: kececitr@yahoo.com

Öz: İnsektisitlerin böcekler üzerindeki etkilerinin belirlenmesi genellikle ölüm oranları dikkate alınarak yapılmaktadır. Bu ise böcek popülasyonlarının insektisitlerden nasıl etkileneceğini ortaya koyan çalışmaların sadece bir bölümünü içermektedir. Bununla birlikte son yıllarda yapılan çalışmalar ile insektisitlerin böceklere etkisinin daha net ortaya konabilmesinin subletal etkilerinin belirlenmesi ile mümkün olabileceği sonucuna varılmıștır. İnsektisitlerin böceklere subletal etkileri, böceklerin gelişimleri, fizyolojileri ve davranışları üzerine olabilmektedir. Bu derleme çalışmasında, farklı etki mekanizmalarına sahip insektisitlerin, farklı böcek türlerine olan subletal etkileri ele alınmıştır.

Anahtar Kelimeler: Pestisit, toksisite, biyolojik etki, fizyolojik etki, doğal düşmanlar

\section{The Sublethal Effects of Pesticides on Insects}

Abstract: Determination of the effects of insecticides on insects is usually done by considering account the mortality rates. This includes only a part of studies that show how insect populations will be affected by insecticides. However, recent studies have concluded that the effect of insecticides on insects can be revealed more clearly by determining the sublethal effects. The sublethal effects of insecticides on insects can be on the development, physiology and behaviour of insects. In this review, the sublethal effects of insecticides with different mechanisms of action on different insect species are discussed.

Keywords: Pesticide, toxicity, biological effects, physiological effects, natural enemies

\section{Giriş}

Zararlılarla mücadelede, kültürel önlemler, biyoteknik mücadele ve biyolojik mücadele gibi alternatif mücadele yöntemlerinin veya kombinasyonlarının kullanıldığg entegre mücadele çalışmalarına rağmen, kimyasal mücadele hala en çok başvurulan mücadele yöntemi olmuştur. Sentetik pestisitlerin 1940'lardaki keşfinden sonra yapılan çalışmalarda, zararlılar üzerindeki öldürücülüğü üzerine odaklanılmıştır. $\mathrm{Bu}$ çalışmalara, son 30 yılda, pestisitlerin doğal düşmanlara olumsuz etkilerinin ele alındığı çalışmalar eklenmiştir. Pestisitlerin böceklere akut toksisite testleri, büyük oranda letal doz ya da konsantrasyon belirleme çalışmaları ile yapılmaktadır. Pestisitlerin gerek zararlılar, gerekse doğal düşmanlara etkilerinin belirlenmesinde medyan letal doz $\left(\mathrm{LD}_{50}\right)$ veya medyan letal konsantrasyon $\left(\mathrm{LC}_{50}\right)$ kullanılmaktadır. Bu değerler, farklı aktif maddeler veya formülasyonların, test organizması üzerine etkilerinin karşılaştırılmasında kullanılan parametrelerdendir. Zararlıların arazi popülasyonları üzerinde tespit edilen $\mathrm{LC}_{50}$ değerleri aynı türün hassas popülasyonlarında tespit edilen $\mathrm{LC}_{50}$ değerleri ile karşılaştırılarak direnç gelişiminin izlenmesinde de yaygın olarak kullanılmaktadır. 
Bununla birlikte, akut toksisite testleri ile belirlenen letal doz ya da konsantrasyon, toksik etkilerin yalnızca bir bölümünü yansıtmaktadır. Genellikle laboratuvar çalışmaları ile belirlenen bu değerler oldukça önemli olmasına rağmen, tarla koşullarında gün 1şı̆̆ı, sıcaklık, yağış vb. nedenlerle böceklerin daha düşük pestisit konsantrasyonlarına maruz kaldığ 1 durumlarda popülasyonlarının nasıl etkileneceğine dair verileri içermemektedir. Pestisitlerin doğrudan öldürücü etkilerinin yanı sıra, düşük pestisit konsantrasyonlarının böceklerin fizyolojileri ve davranışları üzerine etkilerinin belirlenmesi de oldukça önemlidir (Desneux ve ark., 2007).

Subletal etkiler, bir toksik maddenin letal ya da subletal dozlarına veya konsantrasyonlarına maruz kalıp hayatta kalan bireyler ya da popülasyonlarda görülen fizyolojik, demografik ya da davranışsal etkiler olarak tanımlanabilir (De França ve ark., 2017).

Böceklerde subletal etkiler, yaşam süresi, gelişme oranları, popülasyon büyüklüğü, fertilite, yumurta verimi, eşey oranları ve davranışlarda değişiklikler, deformasyonlar, besin ve ovipoziyon alanları arama, beslenme ve ovipozisyon süresinde kısalmalar şeklinde ortaya çıkabilmektedir (Lee, 2000). $\mathrm{Bu}$ nedenle subletal doz ve konsantrasyonların zararlı böcek fizyolojisi, davranışları, demografik parametreler ve doğal düşmanlar üzerindeki etkileri, entegre zararlı mücadele programlarında kullanılmak üzere insektisit seçiminde çok önemli olmaktadır (De França ve ark., 2017).

Subletal etki çalışmalarında kullanılan insektisitler arasında, bitkisel ve biyolojik insektisitler, klorlandırılmış hidrokarbonlar, organik fosforlular, karbamatlar, diamidler, hydrazinler, böcek büyüme düzenleyicileri, neonikotinoidler ve pyrethroidler bulunmaktadır (De França ve ark., 2017). Bu derleme çalışmasında, insektisitlerin böceklerin gelişimleri, fizyolojileri ve davranışları üzerine subletal etkileri hakkında bilgilerin verilmesi amaçlanmıştır.

\section{2. İnsektisitlerin Böcek Gelişimi Üzerine Subletal Etkileri}

Böcek gelişimi üzerinde insektisitlerin subletal dozlarının ve konsantrasyonlarının etkileri, ovipozisyonda azalma, ergin öncesi dönemlerin gelişme sürelerinde uzama ya da yaşam süresinde kısalma gibi yollarla ortaya çıkabilmekte ve gelişimlerini etkileyerek böcek popülasyonlarının sonraki nesillerinde azalmalara neden olabilmektedir (De França ve ark., 2017).

\subsection{Ergin öncesi dönemlerin gelişme süresi, ergin ömür uzunluğu, eşey oranı}

Lufenuron, methoxyfenozide, spinosad, endosulfan, novaluron ve tebufenozide gibi insektisitlerin Anticarsia gemmatalis Hübner (Lepidoptera:Noctuidae) üzerindeki subletal etkileri ergin yaşam süresi ve fertilitesinde azalma olarak gözlemlenmiştir (Storch ve ark., 2007). Hexaflumuron ise, Plutella xylostella (Linnaeus) (Lepidoptera: Plutellidae)'nın ovipozisyon süresi, pupa dönemi süresi ve ergin çıkışında düşüşe neden olmuştur (Mahmoudvand ve ark., 2012). Fenoxycarb'ın predatör Chrysoperla rufilabris Burmeister (Neuroptera: Chrysopidae)'in pupa hariç tüm dönemlerinde gelişim süresini uzattığ 1 bildirilmiştir (Liu ve Chen, 2001).

Cyantraniliprole'ün $\mathrm{LC}_{30}$ konsantrasyonu ise, Helicoverpa assulta Guenee (Lepidoptera: Noctuidae)'da ilk nesilde pupa ağırlığı ve ergin fekonditesinde azalmaya neden olduğu, bununla birlikte sonraki nesillerde pupa periyodu, eşey oranı ve erginlerin yaşam süresini etkilemediği bildirilmektedir (Dong ve ark., 2017). Aynı aktif maddenin Agrotis ipsilon Hufnagel (Lepidoptera: Noctuidae)'da $\quad \mathrm{LC}_{5}, \quad \mathrm{LC}_{20} \quad$ ve $\mathrm{LC}_{40}$ konsantrasyonlarının larva gelişme süresi, pupa süresi ve ortalama döl süresinde uzamaya neden olduğu ifade edilmiştir ( $\mathrm{Xu}$ ve ark., 2016). Cyantraniliprole'un $1 \mathrm{mg} \mathrm{L}^{-1}$ ve $10 \mathrm{mg} \mathrm{L}^{-1}$ gibi düşük letal konsantrasyonlarda, Coccinella septempunctata L. (Coleoptera: Coccinellidae)'ya uygulanması sonrasında, uygulama yapılan bireylerin uygulama yapılmamış kontrol grubu bireyler ile karşılaştırıldığında larva dönemi sürelerinin önemli derecede uzadığ1, ergin yaşam süresinin ise azaldığ 1 belirtilmiştir (Jiang ve ark., 2020). Bemisia tabaci Gennadius (Hemiptera: Aleyrodidae)'ye cyantraniliprole'un $\mathrm{LC}_{10}(0.22 \mathrm{mg}$ $\left.\mathrm{L}^{-1}\right)$ ve $\mathrm{LC}_{25}\left(0.63 \mathrm{mg} \mathrm{\textrm {L } ^ { - 1 }}\right)$ konsantrasyonlar1 uygulandiğında, gelişme süresi artarken nimf, pseudopupa ve ergin dönemlerin hayatta kalma oranının azaldığı gözlemlenmiştir (Wang ve ark., 2017). Ryanodine reseptör modülatörlerinden olan cyantraniliprole'ün genel olarak böceklerin ergin öncesi biyolojik dönemlerinin gelişme süresini uzattığ 1 söylenebilir.

Nesidiocoris tenuis Reuter (Hemiptera: Miridae) erginlerine üç gün boyunca flubendiamide, spirotetramat, deltamethrin, flonicamid, metaflumizone ve sulfoxaflor uygulanmış Ephestia kuehniella Zeller (Lepidoptera: Pyralidae) yumurtaları verilmiştir. Spirotetramat, flonicamid, metaflumizone ve sulfoxaflor ile uygulama yapılmış yumurta ile beslenen bireylerin yaşam süresi (sırasıyla; 14.5, $13.0,7.9$ ve 7.4 gün) kontrol grubu bireylerinin 
yaşam süresi (17.7 gün) ile karşılaştırıldığında azaldığ

Halyomorpha halys Stal. (Hemiptera: Pentatomidae) yumurtalarına azadirachtin + pyrethrin, spinosad, sulfaxoflor, bifenthrin uygulanması sonucu; bifenthrin'in yumurta açılımını önemli derecede düşürdüğü, tüm insektisitlerin yumurta açılımından 5 gün sonra 1 . dönem nimflerde belirgin doğrudan ölüme neden olduğu kaydedilmiştir (Cira ve ark., 2017).

$\mathrm{LC}_{25}$ flupyradifurone uygulanmış $\mathrm{F}_{0}$ Aphis gossypii Glover (Hemiptera: Aphididae) bireylerinden meydana gelen $\mathrm{F}_{1}$ Aphis gossypii jenerasyonunun ergin öncesi dönemlerinin gelişme süresi önemli derecede uzadığı belirlenmiştir (Liang ve ark., 2019).

Bir başka çalışmada spirotetramat uygulaması sonrasında C. septempunctata'nın hayatta kalma oran1, hayatta kalma süresi, fekondite ve yumurta açılma oranında belirgin değişiklikler gözlemlenmezken, clothionidin $\left(>2.5 \mathrm{mg} \mathrm{L}^{-1}\right)$, lambda-cyhalothrin $\left(>0.03 \mathrm{mg} \mathrm{L}^{-1}\right)$ ve bifenthrin $\left(>0.125 \mathrm{mg} \quad \mathrm{L}^{-1}\right)$ uygulandığında ise C. septempunctata larvalarını hayatta kalma, pupa dönemine geçebilme oranında ciddi azalmalar gözlemlenmiştir (Tengfei ve ark., 2019).

Nimf dönemlerinde böcek büyüme düzenleyici (IGR)'ler olan teflubenzuron ve methoxyfenozide maruz kalan Macrolophus basicornis Stal. (Hemiptera: Miridae) $F_{0}$ ve $F_{1}$ dişilerinin tibia uzunluklarında azalma gözlemlenmiştir (Passos ve ark., 2018).

İnsektisitler eşeylerin gelişim süresi ve ergin ömür uzunluğu üzerine farklı tepkilere de neden olabilmektedir. Permethrin'e maruz kalan pentatomid predatör Supputius cincticeps Stal. (Heteroptera: Pentatomidae)'de dişilerin gelişim süresinde kısalma, erkeklerin gelişim süresinde ise uzamaya neden olmuştur (Zanuncio ve ark., 2003). Engytatus varians Distant (Hemiptera: Miridae)'ın üçüncü nimf döneminde teflubenzuron'a maruz kalmış erkeklerde kontrole göre ömür uzunluğunda azalma görülürken, dişilerin ergin ömür uzunluğunda ise bir değişiklik olmadığ1 bildirilmiştir (Perez-Aguilar ve ark., 2018).

İnsektisitlerin parazitoidlerin gelişimi üzerindeki etkileri ile ilgili çalışmalarda en çok pupa döneminden ergin çıkış oranı, ergin öncesi dönemlerin gelişme süresi ve eşey oranı vb. kriterler ele alınmıştır (Schneider ve ark., 2004). Spinosad isimli insektisitin, endoparazitoid Hyposoter didymator Thun.'un parazitlenmiş konukçudan ergin çıkışını azalttığı belirtilmiştir. Bir başka çalışmada, Avermektinler grubundaki bir insektisit olan emamectin benzoat'in sonraki
Trichogramma achaeae Nagaraja \& Nagarkatti (Hymenoptera: Trichogrammatidae) neslinde ergin öncesi gelişme süresinde uzamaya neden olduğu belirtilmiştir (Fontes ve ark., 2018). Ergin öncesi dönemlerin gelişme sürelerinin uzaması, konukçu ile parazitoidin senkronizasyonunun bozulmasına ve parazitoid açısından önemli bir dezavantaj oluşmasına neden olmaktadır (Desneux ve ark., 2007).

İnsektisit uygulaması yapılmış kartlardaki kalıntılara temas eden pupalardan çıkmış parazitoid Trichogramma pretiosum Riley (Hymenoptera: Trichogrammatidae) dişilerinin yaşam süresi kontrol grubu dişilerinde 12.97 gün olan ömür uzunluğunun; acephate, chlorfenapyr, chlorpyriphos ve lambda-cyhalothrin + thiamethoxam için sirasıyla 1.70 gün, 1.30 gün, 1.00 gün ve 8.07 gün düzeylerine kadar düştüğü ve önemli derecede kısaldığı bildirilmiştir. Aynı çalışmada, gelişimlerinin 8 . gününde acephate, chlorpyriphos ve lambda-cyhalothrin + thiamethoxam uygulanmış $T$. pretiosum pupalarından ergin çıkış oranı sırasıyla \% 71.17, $\% 18.07$ ve \% 46.30 olarak gerçekleştiği ve kontrole (\% 90.59) göre önemli derecede azalma olduğu ifade edilmiştir (Paive ve ark., 2018).

Emamectin benzoat'in Trichogramma achaeae'de dişi oranında azalmaya neden olduğu belirtilmiştir (Fontes ve ark., 2018). Chlorpyrifos (LD ${ }_{50}$ 'a maruz kalan Aphytis melinus DeBach (Hymenoptera: Aphelinidae) dişilerin yavrularının $\%$ 58'inin dişi olduğu, kontrol grubunda ise bu oranın \% 73 olduğu bildirilmiștir (Rosenheim ve Hoy, 1988). Aynı insektisitin $\mathrm{LD}_{20}$ dozuna maruz kalip hayatta kalan Trichogramma brassicae Bezdenko (Hymenoptera: Trichogrammatidae)'nin yavrularının \% 61'inin, kontrol grubu yavrularının ise \% 73'ünün dişi olduğu belirtilmiştir (Delpuech ve Meyet, 2003). Benzer sonuçlar, Aphidius uzbekistanicus Luz. (Hymenoptera: Aphidiidae) erginleri iki sentetik pyrethroid insektisit, deltamethrin ve lambda-cyhalothrin'e maruz kaldığında da gözlendiği, eşey oranının, erkekler lehine bozulduğu ifade edilmiştir (Krespi ve ark., 1991). Chlorpyrifos'un cinsiyet oranını dişilerin lehine, deltamethrin ve lambda-cyhalothrin'in ise erkeklerin lehine değiştirmesine rağmen, diğer organik fosforlu ve pyrethroid insektisitlerinde cinsiyet oranını benzer şekilde etkileyebileceğini söylemek mümkün görülmemektedir.

İnsektisitlerin fizyolojik etkileri, cinsiyetin bir fonksiyonu olarak hayatta kalma farklılıkları aracılığıyla faydalı böceklerin cinsiyet oranlarının değişimine neden olabileceği belirtilmektedir. İnsektisitlerin özellikle haploid türlerde istemli bir eylem olan yumurta fertilizasyonu üzerine 
etkisinin olmasının veya ergin öncesi dönemler pestisite maruz kaldığında cinsiyetlerde farklı hayatta kalma oranları gerçekleşmesinin, cinsiyet oranı değişimine neden olabileceği düşünülmektedir (Desneux ve ark., 2007).

\subsection{Yumurtlama/parazitleme kapasitesi}

İnsektisitlerin yumurtlama kapasitesi üzerindeki subletal etkilerinin fizyolojik ve davranışsal nedenlerle olabileceği belirtilmektedir (Desneux ve ark., 2007). Plutella xylostella (Linnaeus) (Lepidoptera: Plutellidae) hexaflumuron'a maruz kaldığında, biraktığı yumurta sayısında azalma görüldüğü bildirilmiştir (Mahmoudvand ve ark., 2012). LC 25 dozunda flupyradifurone uygulanmış $\mathrm{F}_{0}$ Aphis gossypii Glover (Hemiptera:Aphididae) bireylerinden meydana gelen $\mathrm{F}_{1}$ A. gossypii jenerasyonunun yumurtlama kapasitesinin, kontrol grubu bireylerine göre önemli derecede azaldığ 1 kaydedilmiştir (Liang ve ark., 2019).

Chlorfluazuron, flufenoxuron ve teflubenzuron gibi IGR insektisitler, oral yolla Cotesia plutellae Kurdjumov (Hymenoptera: Braconidae) dişilerine verilmiştir. Kontrol grubunda parazitlenmenin \% 68.0 olduğu, IGR uygulanmış dişilerde ise parazitlenme oranının düşüş gösterdiği ve sırasıyla $\% 22.3, \% 41.6$ ve \% 23.7 olduğu kaydedilmiştir. Bunun nedeninin, kesin olarak bilinmemekle birlikte, dişi fertilitesindeki canlı yumurta sayısının azalması ile ilişkili olabileceği belirtilmiştir (Haseeb ve Amano, 2002).

Konukçu içerisindeki 0-24 saatlik Trichogramma pretiosum bireylerine uygulanan tebufenozide ve teflubenzuron'un ergin döneme ulaşan dişilerin parazitleme kapasitesinin yaklaşık yarı yarıya azalmasına neden olduğu ve tebufenozide'de görülen bu azalmanın, vitellogenesis, yumurtlama ve spermatositlerin gelişmesi gibi böceklerin üreme sistemlerindeki fizyolojik aşamalarda görev alan ekdisteroidlerin engellenmesi nedeniyle oluşabileceği bildirilmiştir (Cônsoli ve ark., 1998). Benzer durum bir başka çalışmada da ortaya konmuş; insektisit uygulaması yapılmış kartlardaki acephate, chlorfenapyr, chlorpyriphos ve lambdacyhalothrin+thiamethoxam kalıntılarına temas eden pupalardan çıkmış parazitoid T. pretiosum dişilerinin parazitleme oranı, kontrol grubu dişilerinin parazitleme oranına göre önemli derecede azaldığı rapor edilmiştir (Paive ve ark., 2018).

Micromus tasmaniae Walker (Neuroptera: Hemerobiidae) larvalarına üç adet konvansiyonel insektisit (methyl parathion, azinphos-methyl, cypermethrin) ve üç adet böcek büyüme düzenleyicisi (fenoxycarb, diflubenzuron, tebufenozide) uygulanmıştır. Dişi başına bırakılan yumurta sayisinın sirasiyla kontrol ve konvansiyonel insektisitlerde 546 adet, 462 adet, 411 adet ve 512 adet olduğu, IGR'larda ise bu sayının 326 adet, 271 adet ve 420 adet olarak belirlendiği bildirilmiştir. Özellikle fenoxycarb ve diflubenzuron'un yaşam tablosu parametreleri üzerine etkilerinin, konvansiyonel insektisitlere göre daha fazla olduğu kaydedilmiştir (Rumpf ve ark., 1998).

Nesidiocoris tenuis erginlerine üç gün boyunca flubendiamide, spirotetramat, deltamethrin, flonicamid, metaflumizone ve sulfoxaflor uygulanmış Ephestia kuehniella yumurtaları verilmiştir ve uygulamadan sonraki beş gün boyunca dişilerin bıraktığı günlük yumurta sayıları takip edilmiştir ve kontrol grubu dişilerinin bıraktığı günlük yumurta sayısı (6.0 adet) ile karşılaştırıldığında spirotetramat (5.3 adet) uygulanmış yumurta ile beslenen dişilerin bıraktığ 1 günlük yumurta sayısında ciddi bir azalma gözlemlenmezken; flubendiamide, deltamethrin, flonicamid, metaflumizone ve sulfoxaflor uygulanmış yumurta ile beslenmiş dişilerin bıraktığı günlük yumurta sayısında (sırasıyla; 4.0 adet, 4.3 adet, 3.4 adet, 2.6 adet ve 2.6 adet) ciddi azalmalar gözlemlenmiştir (Wanumen ve ark., 2016).

Bir başka çalışmada azadirachtin, spinosad ve indoxacarb'ın; N. tenuis ve Macrolophus pygmaeus Rambur'un (Hemiptera: Miridae) son dönem nimflerine uygulanması sonucu, $M$. pygmaeus'da spinosad'in, $N$. tenuis'de ise azadirachtin'in sonraki nesil nimf sayılarında ciddi azalmalara neden olduğu görülmüştür (Arno ve Gabarra, 2011).

Bununla birlikte insektisitlere maruz kalan bazı doğal düşmanlarda yumurtlama kapasitelerinin arttığını bildiren çalışmalar da bulunmaktadır. Larva döneminde teflubenzuron'a maruz kalmış, Adalia bipunctuta L. (Coleoptera, Coccinellidae) dișilerinin daha fazla yumurta biraktığ belirlemiştir (Olszak ve ark., 1994).

Genel olarak nörotoksik ve IGR insektisitler karşılaştırıldığında, IGR'ların fekondite üzerine, en az nörotoksik bileşikler kadar etkili olduğu görülmektedir.

\section{3. İnsektisitlerin Böcek Fizyolojisi Üzerine Subletal Etkileri}

İnsektisitlerin subletal dozlarına veya konsantrasyonlarına maruz kalan böceklerin, insektisitlerin sinir sistemlerine etkileri ya da hormonal dengelerinin bozulması ile 
fizyolojilerinin etkilenebileceği ve hayatta kalma ve üreme oranlarının düşebileceği ifade edilmektedir. Potansiyel olarak, insektisitlerin tüm sınıflarının yumurta fertilizasyonu, oogenesis, ovülasyon, spermatogenesis ve sperm mobilitesi gibi fizyolojik parametrelerde subletal etkilere neden olabileceği düşünülmektedir (Haynes, 1988).

\subsection{Bağışıklık sistemine etkileri}

İnsektisitler, böceklerin immun kapasiteleri ile etkileşim içinde olabilir ve böcek türlerine veya insektisite bağlı olarak immun kapasitenin azalışına ya da artışına neden olabilir (Desneux ve ark., 2007).

Monocrotophos ve methyl parathion'un $\mathrm{LC}_{50}$ değerinin onda biri uygulandığında, predatör Rhynocoris kumarii Ambrose ve Livingstone (Hetoroptera, Reduviidae) hemolimfindeki plazmatositlerin sayısında sirayla \% 16 ve \% 13 azalma görülürken, endosulfan uygulandığında bu sayıda \% 15 artış görülmüştür. Plazmatositler, böceklerin yabancı maddelerin enkapsülasyonunu sağlayan immun tepkilerinde önemli bir role sahiptir. Plasmatositlerin sayısındaki azalışın, fagositoz boyunca detoksifikasyonda rol oynayan granülar hemositlerin sayısındaki artış ile bağlantılı olduğu bildirilmiştir. Plasmatositlerin detoksifikasyon işlemi sırasında granüler hemositlere dönüştürüldüğü, test edilen pestisitlerin detoksifikasyonu için bağışıklık hücrelerinin dolaylı olarak harekete geçirilmesiyle, avcı böcekte bağışıklık tepkisinin oluştuğu tezi öne sürülmüştür (Edward George ve Ambrose 2004). Konukçu-parazitoid ilişkilerinde insektisitler, konukçunun immun reaksiyonunun azalması yoluyla parazitoidleri dolaylı olarak etkilemektedir (Desneux ve ark., 2007). $\mathrm{LD}_{30}$ değerleri uygulanan dieldrin ve endosulfan'1n, Drosophila melanogaster Meigen (Diptera: Drosophilidae)'in larvalarında, parazitoidi olan Leptopilina boulardi (Barbotin, Carton ve Kelmer-Pillault) (Hymenoptera, Eucoilidae)'ye karşı gösterdiği immun reaksiyonda sirasiyla $\% 25$ ve $\% 23$ azalmaya neden olduğu ortaya konmuştur. Endosulfan'ın ayrıca, enkapsülasyon oranında da \% 26 azalmaya da neden olduğu ifade edilmiştir (Delpuech ve ark., 1996). Tam tersine insektisitler parazitoid larvalarının enkapsülasyonunda artışa da sebep olabilirler. Aynı parazitoidin chlorpyrifos'un $\mathrm{LD}_{50}$ değerine maruz kaldığında, yumurtalarının enkapsülasyonunda $\% \quad 4.5 \quad$ artış olduğu kaydedilmiştir (Delpuech ve Tekinel-Ozalp, 1991).

Monocrotophos, methyl parathion ve chlorpyrifos böceklerin immun tepkisinde artışa yol açarken endosulfan ve dieldrin azalmaya neden olmuştur. Bununla birlikte, diğer organik fosforlu ve klorlandırılmış hidrokarbonluların benzer sonuçlara yol açacağını düşünmek mümkün görülmemektedir.

\subsection{Genel biyokimya ve nörofizyoloji üzerine etkileri}

İnsektisitlerin böcek kimyası üzerine etkisini ele alan çalışmalar, biyokimyasal sistemleri daha iyi bilinen bal arıları üzerine yoğunlaşmıştır. Bu çalışmalarda genel olarak insektisitlerin uygulanması sırasında veya sonrasında enzim aktivitelerinin ölçülmesi hedeflenmiştir. Fenitrothion ve cypermethrin bal arılarına uygulandiktan sonra, $\mathrm{Na}^{+} / \mathrm{K}^{+}$-ATPaz ve asetilkolinesteraz (AChE) aktivitelerinde azalma görüldüğü ifade edilmiştir. Özellikle cypermethrin'in $1 \mathrm{nmol}$ arl $^{-1}$ dozunda $\mathrm{Na}^{+} / \mathrm{K}^{+}$ATPaz aktivitesinin \% 45 oranında azaldığ belirlenmiştir. $\mathrm{Na}^{+} / \mathrm{K}^{+}$ATPaz'ın, hücre gerilimini düzenleyerek iyonik konsantrasyon dengesini belirleyen ve hücre metabolizması için gerekli olan enerjiyi serbest bırakan transmembran bir enzim olduğu gösterilmiştir. Pyrethroidler tarafından tetiklenen $\mathrm{Na}^{+} / \mathrm{K}^{+}$karşılıklı değişiminin engellenmesi ile, çok sayıda hücresel fonksiyonların etkilenmesine neden olabileceği belirtilmektedir. Deltamethrin'in miyokardiyal hücrelerde belirgin fonksiyon bozukluğuna sebep olması buna örnek olarak verilmektedir (Desneux ve ark., 2007).

Pestisitlerin doğal düşmanlardaki biyokimyasal etkilerinin belirlenmesine yönelik sınırlı sayıda çalışma bulunmaktadır. Rumpf ve ark. (1997), Chrysoperla carnea Stephens (Neuroptera: Chrysopidae) ve M.tasmaniae Walker ile yaptıkları çalışmada AChE derecesi ve glutathionS-transferaz (GSTs) inhibisyonu arasındaki korelasyonu göstererek, verilen insektisitlerin neden olduğu ölüm oranının, toksine spesifik olduğu gibi türe de spesifik olduğunu ortaya koymuşlardır. Methyl-parathion veya azinphosmethyl'e maruz kalan M. tasmaniae'de AChE inhibisyonu 24 saat içinde artmıştır. Bununla birlikte C. carnea'da AChE inhibisyonu sinırl düzeylerde kalmıştır. Bu da C. carnea'nın organik fosforlulara toleransını göstermektedir (Rumpf ve ark., 1997).

Kaslardaki ryanodine reseptörlerini ve kalsiyum kanallarını hedefleyen diamidler sınıfından bir insektisit olan cyantraniliprole'un iki subletal konsantrasyonunun ( $\mathrm{LC}_{10}$ ve $\left.\mathrm{LC}_{25}\right)$ Spodoptera exiqua (Hübner) (Lepidoptera: Noctuidae) da enzim aktivitelerine etkisi incelenmiş; her iki subletal konsantrasyonda da başlangıçta, carboxylesteraz ve glutathione-Stransferaz enzimlerinin aktivitelerinde artış görülürken, 24-96 saat arasında ise azalmaya 
neden olduğu belirlenmiştir (Yu ve ark., 2015). Ancak chlorpyrifos ve methomyl'in subletal dozlar1 Spodoptera littoralis (Boisduval) (Lepidoptera: Noctuidae) larvasının başında AChE aktivitesinde değişikliğe sebep olmamıştır (Dewer ve ark., 2016). Bu durum ise S. littoralis'in, böceklerde AChE inhibisyonuna sebep olan organik fosforlu ve karbamatlı insektisitlerin subletal değerlerine toleranslı olduğunu göstermektedir.

Chilo suppressalis Walker (Lepidoptera: Crambidae)'in larvalarına uygulanan $\mathrm{LC}_{10}$ ve $\mathrm{LC}_{30}$ chlorantraniliprole çeşitli biyolojik dönemlerinin deri değiştirme hormonu seviyesinde kontrol grubu bireyleriyle karşılaştırıldığında azalmalara neden olmuştur (Meng ve ark., 2020).

\section{4. İnsektisitlerin Böcek Davranışları Üzerine Subletal Etkileri}

İnsektisitlerin subletal dozlarına ya da konsantrasyonlarına maruz kalmak böceklerin besin arama, ovipozisyon alanı seçme, feromonal iletişimler gibi birçok davranışsal parametrelerinde değişikliğe neden olabilir (De França ve ark., 2017).

\subsection{Hareketlilik üzerine etkileri}

Insektisitlere maruz kaldiktan sonra faydalı arthopodların mobilitesindeki değişimler doğrudan çalışılmamıştır. Ayrıca çalışmalar genellikle kesin ölçümler ile kantitatif veriler ya da istatistiksel analizler aracılığıyla yapılmamıştır (Desneux ve ark., 2007).

Predatör, C. septempunctata'nın, insektisitin neden olduğu iritasyon sebebiyle deltamethrin püskürtülmüş bir alanda serbest bırakıldığında daha sık yürüme ve ortamı tarama faaliyeti gösterdiği belirlenmiştir (Wiles ve Jepson, 1994). Mobilitenin artışı ile ilişkili olan tarama davranışına böcek vücudunun yüzeyinde bulunan kemoreseptörlerin iritasyonu ile refleks hareketinin başlamasının neden olduğu düşünülmektedir. Bu nedenle, artmış mobilitenin doğal düşman etkinliği ile ilişkili olmayabileceği ifade edilmiştir. Bunun aksine avcının mobilitesindeki azalmanın kendisini diğer avcılara karşı hassas hale getirebileceği belirtilmiştir (Desneux ve ark., 2007).

Topikal olarak imidacloprid uygulanmış işçi arıların konumu (arının vertikal yer değiştirmesi) ve inaktif oldukları süreler, kontrol grubu ile karşılaştırılmıştır. İmidacloprid'in en düşük dozunun (1.25 ng $\mathrm{arl}^{-1}$ ) koku fonksiyonları üzerine herhangi bir etkisi olmamışken, motor aktivitelerinde artışa neden olmuştur. Bununla birlikte daha yüksek dozlar (2.5-20.0 ng $\left.\mathrm{arr}^{-1}\right)$ arıların arenadaki yer değiştirmelerinde azalmaya neden olmuştur (Lambin ve ark., 2001).

\subsection{Navigasyon/oryantasyon üzerine etkileri}

Arama/bulma gibi davranışlar genel olarak besinini arayan bitki zararlısı böcekler ve sosyal böcekler ile avını veya konukçusunu arayan doğal düşmanlarda oldukça önemlidir. Bununla birlikte navigasyon hem besin bulma hem de yuvaya dönme konusunda zorunluluğu bulunan ar1, karınca vb. sosyal böceklerde daha da ön plana çıkmaktadır.

Doğal düşmanlar hayatlarının önemli bir kısmını konukçu ya da av arayarak geçirirler. Doğal düşmanlarda yer ve yön bulma, kimyasal ya da görsel birçok duyusal belirteçlerden faydalanılarak yürütülmektedir. Yer/yön bulma ve gezinme tümüyle sinir sistemi tarafından yönetilir. Nörotoksik insektisitler ise farklı etki şekilleri ile sinirsel iletime etki ederek böceklerin bu davranışlarını etkileyebilmektedir (Desneux ve ark., 2007).

Aphidius rhopalosiphi DeStefani-Perez (Hymenoptera: Braconidae)'nin, Sitobion avenae (F.) (Hemiptera:Aphididae) tarafindan salgilanan balımsı madde bulunan ve deltamethrin'in uygulaması yapılan arenada davranışı incelenmiștir. Normalde parazitoid net bir biçimde balımsı madde rotasını izleyebilirken, artan deltamethrin dozlarında balımsı madde rotasından erken ayrılma davranışı göstermiştir (Longley ve Jepson, 1996).

Parazitoid Microplitis croceipes Cresson (Hymenoptera: Braconidae), imidacloprid uygulamasından 2 gün sonra pamuk bitkisinin extrafloral nektarı ve kontrol bitkisi extrafloral nektarının bulunduğu bir rüzgar tünelinde denemeye alınmış, kontrol grubu parazitoidlerinde uçuş tepkisi, \% 79.2 olurken, imidacloprid ile kontamine nektarda bu oran \% 23.5 olarak gerçekleşmiş ve ilaçlı nektara verdiği tepki \% 70.3 oranında azalmıştır (Stapel ve ark., 2000).

Polinatörler için, işaretlerin görsel olarak öğrenilmesi mekansal yön bulmada önemlidir. Balarıları, görsel işaretleri bir yiyecek kaynağının yerini bulmak için kullandığı gibi, yiyecek kaynağına ulaşmak üzere uçan diğer bireylere yiyecek kaynağının yönünü ve mesafeyi kesin olarak iletmek için de kullanılır (Von Frisch, 1967). Bir balarısının tarama gezisi boyunca insektisit maruziyeti, görsel desenleri yanlış bir şekilde elde edip birleştirmesine, oryantasyon bozukluğuna ve kaybına neden olabilir. İnsektisitler, insektisite maruz kalmış arayıcıların oryantasyon davranışını zayıflatmasının yanı sıra geri dönen arayıcıların uçuşları boyunca 
bildirdikleri bilginin doğruluğunu etkileyebilmektedir (Desneux ve ark., 2007).

\section{Sonuçlar}

İnsektisitlerin ruhsatlandırılması aşamalarında, böceklere letal etkilerinin belirlenmesine yönelik çalışmaların ön plana çıktığı görülmektedir. Herhangi bir nedenle daha düşük insektisit dozlarına maruz kalan böceklerin, ergin öncesi dönemlerin gelişme süresi, ergin ömür uzunluğu, fekondite, erkek:dişi oranı vb. biyolojik parametrelerin yanı sıra, vücutlarındaki fizyolojik değişimler de olumlu veya olumsuz yönde etkilenmektedir. Davranışsal özelliklerinin de etkilenen bir başka parametre olduğu düşünüldüğünde, insektisitlerin böcekler üzerine karmaşık ve çok yönlü subletal etkilerinin olduğu ortaya çıkmaktadır. Sadece bitki-herbivor böcek arasındaki iki yönlü ilişkilerde insektisitlerin subletal etkilerinin ortaya konulması açısından daha kolay yöntemler belirlenebilir. Ancak bir de hedef dışı organizmalar olan polinatör veya faydalı böceklerin de dâhil olduğu üçlü ilişkinin insektisitlerden nasıl etkileneceğinin ortaya konması için çok sayıda parametrenin göz önüne alınması gerekmektedir. Genellikle bu çalışmaların gerek zahmetli, gerekse fazla iş gücü ve zaman isteyen çalışmalar olması nedeniyle göz ard1 edildiği düşünülmektedir. Dahası bu çalışmaların eksikliği, hedef dışı organizmalara insektisitlerin subletal etkilerinin tam olarak ortaya konabileceği, standart hale gelmiş metotlarında sınırlı sayıda kalmasına neden olmuştur.

İnsektisitlerin etki mekanizmasına göre, birkaç insektisiti ve birkaç böceği ele alıp genel bir kanıya gitmekte mümkün değildir. Örneğin sistemik bir insektisitin sadece zoofag özelliği olan bir avcı üzerindeki subletal etkileri, aynı zamanda fitofag karaktere de sahip bir avcı veya bir yumurta parazitoidi üzerinde tamamen farklı etkilere neden olabilmektedir. İnsektisitlerin zararlı böceklerin yanı sıra, doğal düşmanlar üzerindeki subletal etkilerin belirlenmesi, insektisitlerin entegre zararlı yönetimi programlarının daha etkin ve sürdürülebilir olarak kullanımına yardımcı olacaktır. $\mathrm{Bu}$ nedenle insektisitlerin subletal etkilerinin belirlenmesi ve uygun metodolojilerin ortaya konması oldukça fazla önem arz etmektedir.

\section{Kaynaklar}

Arno, J., Gabarra, R., 2011. Side effects of selected insecticides on the Tuta absoluta (Lepidoptera: Gelechiidae) predators Macrolophus pygmaeus and Nesidiocoris tenuis (Hemiptera: Miridae). Journal of Pest Science, 84(4): 513-520.
Cira, T.M., Burkness, E.C., Koch, R.L., Hutchison, W.D., 2017. Halyomorpha halys mortality and sublethal feeding effects following insecticide exposure. Journal of Pest Science, 90(4): 12571268.

Cônsoli, F.L., Parra, J.R.P., Hassan, S.A., 1998. Sideeffects of insecticides used in tomato fields on the egg parasitoid Trichogramma pretiosum Riley (Hym., Trichogrammatidae), a natural enemy of Tuta absoluta (Meyrick) (Lep., Gelechiidae). Journal of Applied Entomology, 122(1-5): 43-47.

De França, S.M., Breda, M.O., Barbosa, D.R.S., Araujo, A.M.N., Guedes, C.A., 2017. The sublethal effects of insecticides in insects. In: V.D.C. Shields (Ed.), Biological Control of Pest and Vector Insects, IntechOpen, London, pp. 23-39.

Delpuech, J.M., Meyet, J., 2003. Reduction in the sex ratio of the progeny of a parasitoid wasp (Trichogramma brassicae) surviving the insecticide chlorpyrifos. Archives of Environmental Contamination and Toxicology, 45(2): 203-208.

Delpuech, J.M., Tekinel-Ozalp, P., 1991. Epigenetic influences of insecticide on host parasitoid relations. Redia, 74(3, Appendix): 417-424.

Delpuech, J.M., Frey, F., Carton, Y., 1996. Action of insecticides on the cellular immune reaction of Drosophila melanogaster against the parasitoid Leptopilina boulardi. Environmental Toxicology and Chemistry: An International Journal, 15(12): 22672271.

Desneux, N., Decourtye, A., Delpuech, J.M., 2007. The sublethal effects of pesticides on beneficial arthropods. Annual Review Entomology, 52: 81-106.

Dewer, Y., Pottier, M.A., Lalouette, L., Maria, A., Dacher, M., Belzunces, L.P., Kairo, G., Renault, D., Maibeche, M., Siaussat, D., 2016. Behavioral and metabolic effects of sublethal doses of two insecticides, chlorpyrifos and methomyl, in the Egyptian cotton leafworm, Spodoptera littoralis (Boisduval) (Lepidoptera: Noctuidae). Environmental Science and Pollution Research, 23(4): 3086-3096.

Dong, J., Wang, K., Li, Y., Wang, S., 2017. Lethal and sublethal effects of cyantraniliprole on Helicoverpa assulta (Lepidoptera: Noctuidae). Pesticide Biochemistry and Physiology, 136: 58-63.

Edward George, P., Ambrose, D.P., 2004. Impact of insecticides on the haemogram of Rhynocoris kumarii Ambrose and Livingstone (Hem., Reduviidae). Journal of Applied Entomology, 128(910): 600-604.

Fontes, J., Roja, I.S., Tavares, J., Oliveira, L., 2018. Lethal and sublethal effects of various pesticides on Trichogramma achaeae (Hymenoptera: Trichogrammatidae). Journal of Economic Entomology, 111(3): 1219-1226.

Haseeb, M., Amano, H., 2002. Effects of contact, oral and persistent toxicity of selected pesticides on Cotesia plutellae (Hym., Braconidae), a potential 
parasitoid of Plutella xylostella (Lep., Plutellidae). Journal of Applied Entomology, 126(1): 8-13.

Haynes, K.F., 1988. Sublethal effects of neurotoxic insecticides on insect behavior. Annual Review of Entomology, 33(1): 149-168.

Jiang, J., Wang, Y., Mu, W., Zhang, Z., 2020. Sublethal effects of anthranilic diamide insecticides on the demographic fitness and consumption rates of the Coccinella septempunctata (Coleoptera: Coccinellidae) fed on Aphis craccivora. Environmental Science and Pollution Research, 27(4): 4178-4189.

Krespi, L., Rabasse, J., Dedryver, C., Nenon, J., 1991. Effect of three insecticides on the life cycle of Aphidius uzbekistanicus Luz. (Hym., Aphidiidae). Journal of Applied Entomology, 111(1-5): 113-119.

Lambin, M., Armengaud, C., Raymond, S., Gauthier, M., 2001. Imidacloprid-induced facilitation of the proboscis extension reflex habituation in the honeybee. Archives of Insect Biochemistry and Physiology: Published in Collaboration with the Entomological Society of America, 48(3): 129-134.

Lee, C.Y., 2000. Sublethal effects of insecticides on longevity, fecundity and behaviour of insect pests: a review. Journal of Biosciences, 11(1): 107-112.

Liang, P.Z., Ma, K.S., Chen, X.W., Tang, C.Y., Xia, J., Chi, H., Gao, X.W., 2019. Toxicity and sublethal effects of flupyradifurone, a novel butenolide insecticide, on the development and fecundity of Aphis gossypii (Hemiptera: Aphididae). Journal of Economic Entomology, 112(2): 852-858.

Liu, T.X., Chen, T.Y., 2001. Effects of the insect growth regulator fenoxycarb on immature Chrysoperla rufilabris (Neuroptera: Chrysopidae). Florida Entomologist, 84(4): 628-633.

Longley, M., Jepson, P.C., 1996. The influence of insecticide residues on primary parasitoid and hyperparasitoid foraging behaviour in the laboratory. Entomologia Experimentalis et Applicata, 81(3): 259-269.

Mahmoudvand, M., Abbasipour, H., Garjan, A.S., Bandani, A.R., 2012. Decrease in pupation and adult emergence of Plutella xylostella (L.) treated with hexaflumuron. Chilean Journal of Agricultural Research, 72(2): 206-211.

Meng, X., Zhang, N., Yang, X., Miao, L., Jiang, H., Ji, C., Xu, B., Qian, K., Wang, J., 2020. Sublethal effects of chlorantraniliprole on molting hormone levels and mRNA expressions of three Halloween genes in the rice stem borer, Chilo suppressalis. Chemosphere, 238: 124676.

Olszak, R., Pawlik, B., Zajac, R., 1994. The influence of some insect growth regulators on mortality and fecundity of the aphidophagous coccinellids Adalia bipunctata L. and Coccinella septempunctata L.(Col., Coccinellidae). Journal of Applied Entomology, 117(1-5): 58-63.

Paive, A.C.R., Beloti, V.G., Yamamoto, P.T., 2018. Sublethal effects of insecticides used in soybean on the parasitoid Trichogramma pretiosum. Ecotoxicology, 27(4): 448-456.
Passos, L.C., Soares, M.A., Collares, L.J., Malagoli, I., Desneux, Carvalho, G.A., 2018. Lethal, sublethal and transgenerational effects of insecticides on Macrolophus basicornis, predator of Tuta absoluta. Entomologia Generalis, 38(2): 127-143.

Pérez-Aguilar, D.A., Soares, M.A., Passos, L.C., Martínez, A.M., Pineda, S., Carvalho, G.A., 2018. Lethal and sublethal effects of insecticides on Engytatus varians (Heteroptera: Miridae), a predator of Tuta absoluta (Lepidoptera: Gelechiidae). Ecotoxicology, 27(6): 719-728.

Rosenheim, J.A., Hoy, M.A., 1988. Sublethal effects of pesticides on the parasitoid Aphytis melinus (Hymenoptera: Aphelinidae). Journal of Economic Entomology, 81(2): 476-483.

Rumpf, S., Frampton, C., Dietrich, D.R., 1998. Effects of conventional insecticides and insect growth regulators on fecundity and other life-table parameters of Micromus tasmaniae (Neuroptera: Hemerobiidae). Journal of Economic Entomology, 91(1): 34-40.

Rumpf, S., Hetzel, F., Frampton, C., 1997. Lacewings (Neuroptera: Hemerobiidae and Chrysopidae) and integrated pest management: enzyme activity as biomarker of sublethal insecticide exposure. Journal of Economic Entomology, 90(1): 102-108.

Schneider, M., Smagghe, G., Pineda, S., Vinuela, E., 2004. Action of insect growth regulator insecticides and spinosad on life history parameters and absorption in third-instar larvae of the endoparasitoid Hyposoter didymator. Biological Control, 31(2): 189-198.

Stapel, J., Cortesero, A., Lewis, W., 2000. Disruptive sublethal effects of insecticides on biological control: altered foraging ability and life span of a parasitoid after feeding on extrafloral nectar of cotton treated with systemic insecticides. Biological Control, 17(3): 243-249.

Storch, G., Loeck, A., Borba, R., Magano, D., Moraes, C., Grutzmacher, C., 2007. The effect of sub-lethal doses of insecticides on artificial diet and caterpillars of Anticarsia gemmatalis (Lepidoptera: Noctuidae). Revista Brasileira de Agrociência, 13(2): 175-179.

Tengfei, L., Yao, W., Lixia, Z., Yongyu, X., Zhengqun, Z., Wei, M., 2019. Sublethal effects of four insecticides on the seven spotted lady beetle (Coleoptera: Coccinellidae). Journal of Economic Entomology, 112(5): 2177-2185.

Von Frisch, K., 1967. The Dance Language and Orientation of Bees. Cambridge University Press, Cambridge.

Wang, R., Zhang, W., Che, W., Qu, C., Li, F., Desneux, N., Luo, C., 2017. Lethal and sublethal effects of cyantraniliprole, a new anthranilic diamide insecticide, on Bemisia tabaci (Hemiptera: Aleyrodidae) MED. Crop Protection, 91: 108-113.

Wanumen, A.C., Sanchez-Ramos, I., Vinuela, E., Medina, P., Adan, A., 2016. Impact of feeding on contaminated prey on the life parameters of Nesidiocoris tenuis (Hemiptera: Miridae) Adults. Journal of Insect Science, 16 (1): 103. 
Wiles, J.A., Jepson, P.C., 1994. Sub-lethal effects of deltamethrin residues on the within-crop behaviour and distribution of Coccinella septempunctata. Entomologia Experimentalis et Applicata, 72(1): 3345.

Xu, C., Zhang, Z., Cui, K., Zhao, Y., Han, J., Liu, F., $\mathrm{Mu}, \mathrm{W} ., 2016$. Effects of sublethal concentrations of cyantraniliprole on the development, fecundity and nutritional physiology of the black cutworm Agrotis ipsilon (Lepidoptera: Noctuidae). Plos One, 11(6): e0156555.
Yu, H., Xiang, X., Yuan, G., Chen, Y., Wang, X., 2015. Effects of sublethal doses of cyantraniliprole on the growth and development and the activities of detoxifying enzymes in Spodoptera exigua (Lepidoptera: Noctuidae). Acta Entomologica Sinica, 58(6): 634-641.

Zanuncio, T.V., Serrão, J.E., Zanuncio, J.C., Guedes, R.N.C., 2003. Permethrin-induced hormesis on the predator Supputius cincticeps (Stål, 1860) (Heteroptera: Pentatomidae). Crop Protection, 22(7): 941-947 